\title{
ANALISA DAN PERANCANGAN SISTEM INFORMASI PENGOLAHAN DATA PASIEN RAWAT JALAN BERBASIS WEB DI PUSKESMAS DESA TANAH MERAH
}

\author{
${ }^{1}$ Alek Setiawan, ${ }^{2}$ llyas \\ 1,2, Program Studi Sistem Informasi, Fakultas Teknik dan IImu Komputer \\ Universitas Islam Indragiri (UNISI) \\ Jl. Provinsi No. 01 Tembilahan Hulu, Indragiri Hilir, Riau - Indonesia \\ Email: aleksetiawan01@gmail.com, ilyasdaeng74@gmail.com
}

\begin{abstract}
Puskesmas Tanah Merah adalah sebuah pusat pelayanan kesehatan yang terdapat di Kuala Enok Kecamatan Tanah Merah. Jumlah pasien di hadapakan pada masalah administrasi diantaranya masalah kartu pasien yang selalu tertinggal, pencatatan data pasien, pencatatan obatobat, dan pembuat laporan data jumlah penyakit. Setiap hari petugas pencatatan data pasien harus mencari kartu pasien yang datang memeriksakan diri ke puskesmas, jika pasien yang tidak mempunyai kartu berobat maka petugas puskesmas akan membuatkan kartu baru. Proses pencarian dan pembuatan kartu pasien ini memakan waktu yang lama. Dengan adanya sistem informasi berbasis web akan memberi kemudahan bagi petugas dan pasien yang berobat. Pelayanan dari segi waktu yang cepat dan efesien sistem informasi data pasien berbasis web akan memberi kemudahan masyarakat.
\end{abstract}

Kata kunci : Puskesmas, Sistem Informasi, WEB, Unified Modelling Language (UML)

\section{PENDAHULUAN}

Puskesmas adalah sebuah tempat alternatif berobat bagi masyarakat selain rumah sakit. Dari segi biaya yang murah keberadaan puskesmas hampir ada di setiap kecamatan dalam proses pelayanan kesehatan puskesmas juga memiliki dokter yang ahli di bidangnya masing-masing dalam kemajuan teknologi sekarang initelah membuat manusiabekerja dengan tepat dan akurat.

Puskesmas tanah merah kecamatan tanah merah memiliki lemari yang besar dengan ribuan kartu pasien. Jumlah pasien di hadapakan pada masalah administrasi diantaranya masalah kartu pasien yang selalu tertinggal, pencatatan data pasien, pencatatan obat-obat, dan pembuat laporan data jumlah penyakit. Setiap hari petugas pencatatan data pasien harus mencari kartu pasien yang datang memeriksakan diri ke puskesmas, jika pasien yang tidak mempunyai kartu berobat maka petugas puskesmas akan membuatkan kartu baru.

Selain dari administrasi kartu yang kurang baiktersebut pencatatan data pasien dikecamatan tanah merah masih dilakukan secara manual dengan mencatat setiap hasil data pasien kedalam buku catatan yang kecil.hal ini antara lain minim nya sistem yang handal untuk merekam data pemeriksaan pasien informasi yang disimpan belum terlalu lengkap terlebih dari pencatatan data pasien yang masih dilakukan secara manual sering kali terbentur ke kurang telitian atau kekurang akuratan manusia (human eror) Proses pembuatan laporan perbulan nya juga menjadi masalah tersendiri bagi petugas pencatatan data pasien karena memakan waktu yang lama untuk membuat laporan.

Dengan adanya sistem informasi berbasis web akan memberi kemudahan bagi petugas dan pasien yang berobat. Pelayanan dari segi waktu yang cepat dan efesien sistem informasi data pasien berbasis web akan memberi kemudahan masyarakat dalam mendaftar,mengetahui dokterdokter yang ada di puskesmas dan mengetahui kegiatan-kegiatan yang akan dilakasanakan oleh pihak puskesmas serta dapat menghasilkan laporan-laporan valid dan terjamin serta menjaga data pasien agar tetap terjaga lebih baik. 


\section{LANDASAN TEORI}

\subsection{Konsep Dasar Sistem Informasi}

Sebuah sistem informasi merupakan kumpulan dari perangkat keras dan perangkat lunak komputer serta perangkat manusia yang akan mengolah data menggunakan perangkat keras dan perangkat lunak tersebut. Selain itu juga data memegang peranan yang penting dalam sistem informasi. Data yang akan dimasukkan adalah sebuah sistem informasi dapat berupa formulirformulir, prosedur-prosedur dan bentuk data lainnya (Kristanto, 2008).

\subsection{Konsep Dasar Sistem}

Sistem juga merupakan kumpulan elemen-elemen yang saling berkaitan dan bekerjasama untuk memproses masukan-masukan tersebut dan mengolah masukan tersebut sampai menghasilkankeluaran (output) yang dinginkan (Kristanto, 2008).

\subsection{Konsep Dasar Informasi}

Informasi adalah data yang telah diklasifikasi atau diinterprestasi untuk digunakan dalam proses pengambilan keputusan. Sistem pengolahan informasi mengolah data menjadi informasi atau tepatnya mengolah data dari bentuk tak berguna menjadi berguna bagi penerimanya.Nilai informasi berhubungan dengan keputusan maka informasi menjadi tidak diperlukan keputusan dapat berkisar dari keputusan berulang sederhana sampai keputusan strategis jangka panjang.Nilai informasi dilukiskan paling berarti dalam konteks sebuah keputusan (Sutabri, 2012).

\subsection{Data}

Data dapat dianalogikan dengan sejumlah blok yang bisa digunakan anak-anak untuk membentuk berbagai struktur sesuai dengan imajinasi mereka. Melalui suatu proses, blok-blok dapat digunakan untuk menyusun struktur/model. Senada dengan itu data yang terdapat dalam suatu organisai dapat diolah sehingga menghasilkan informasi yang bisa digunakan oleh para eksekutif diorganisasi untuk membantu pengambilan keputusan. Secara konsep, data adalah deskripsi tentang benda, kejadian, aktivitas, dan transaksi, yang tidak mempunyai makna tau tidak berpengaruh secara langsung kepada pemakai. Data dapat berupa nilai yang terformat, teks, citra, audio, dan video. Data yang terformat adalah data dengan sustu format tertentu, misalnya data yang menyatakan tanggal atau jam, atau menyatakan nilai nilai mata uang (Kadir, 2014).

\subsection{Rawat Jalan}

Rawat jalan adalah pelayanan keperawatan kesehatan perorangan yang meliputi observasi, diagnose, pengobatan, rehabilitas medik tanpa tinggal di ruang inap pada sarana kesehatan (Perda Provinsi Jateng, 2011).

Menurut surat keputusan Mentri RI no. 560/MENKES/SK/IV2003 tentang tarif perjam rumah sakit bahwa rawat jalan adalah pelayanan pasien untuk observasi, diagnose, pengobatan, rehabilitas medik dan pelayanan kesehatan lainnya tanpa menginap di rumah sakit (Fajarita, dkk, 2014).

\section{ANALISA DAN PERANCANGAN}

Usecase diagram akan memperlihatkan bagaimana peranan setiap aktor dalam interaksi dengan sistem. Usecase diagram untuk sistem yang dikembangkan dapat dilihat pada gambar dibawah ini. 


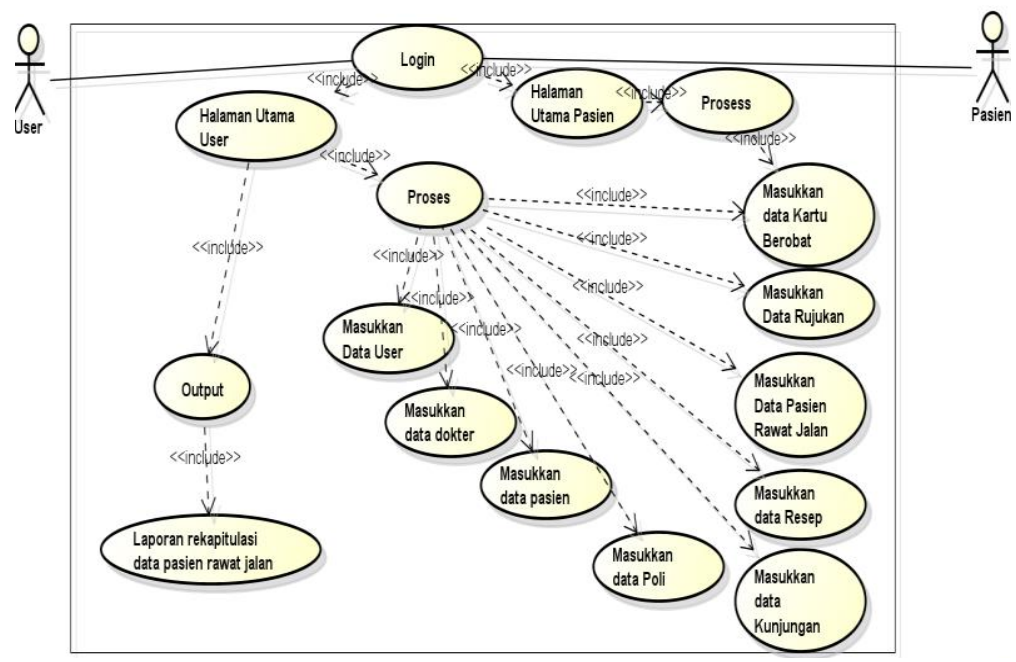

Gambar 1. Use Case Diagram Sistem Informasi Puskesmas

Class diagram menggambarkan kelas-kelas objek yang menyusun sebuah sistem dan juga hubungan antar kelas objek. Kelas tersebut dibentuk oleh entitas atau objek yang mempunyai atribut dan operasi. Dari kelas tersebut dapat terbentuk sebuah tabel yang dapat berasosiasi dengan tabel lainnya, sehingga memungkinkan terbentuknya sebuah database.

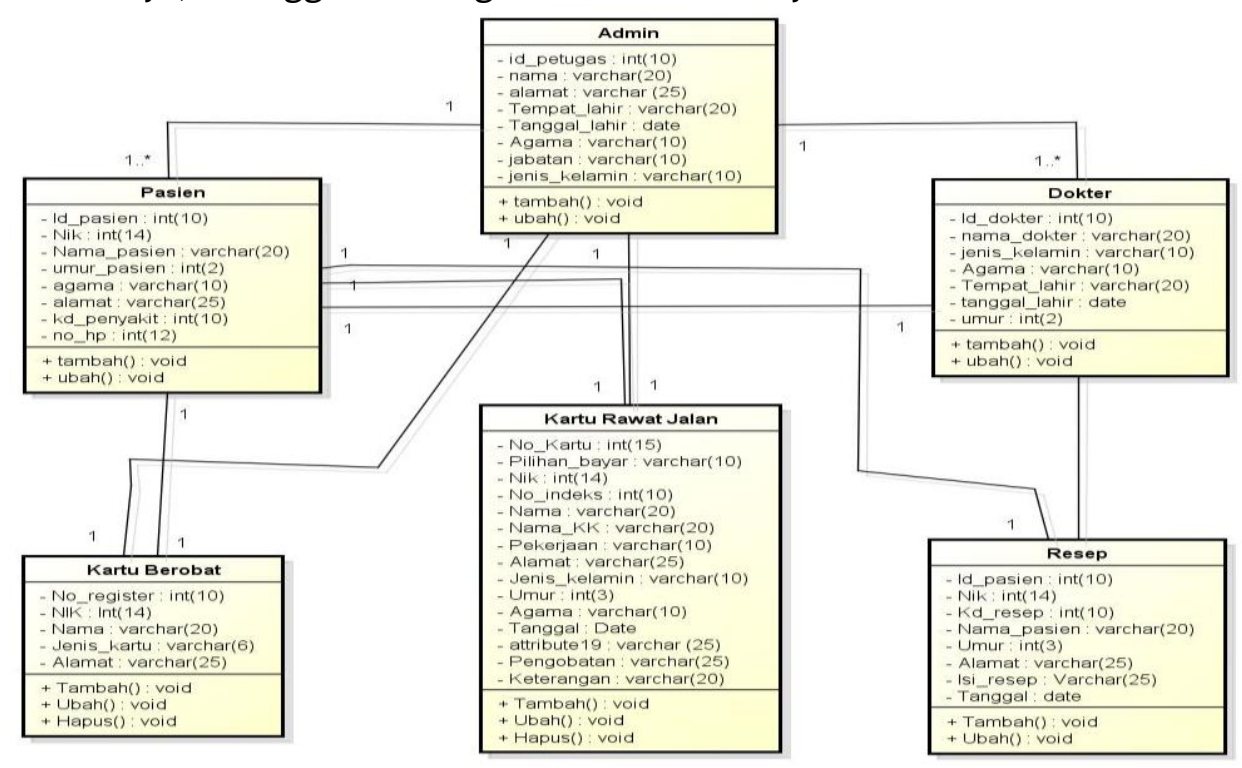

\section{Gambar 2. Desain Class Diagram}

\section{HASIL DAN IMPLEMENTASI}

Implementasi merupakan tahapan menerapkan dan mengoperasikan sistem pada keadaan yang sebenarnya, sehingga akan diketahui apakah sistem yang telah dibangaun benar-benar dapat berjalan dengan tujuan dan sesuai dengan tujuan yang ingin dicapai.

\subsection{Form Menu Utama}

Halaman ini bisa juga disebut dengan form home bagian ini berisikan menu-menu yang memiliki link ke modul-modul program. Selain itu juga untuk menampilkan data-data yang berkaitan dengan data puskesmas dan data pasien. Adapun lebih jelasnya dapat dilihat tampilan formnya seperti dibawah ini. 


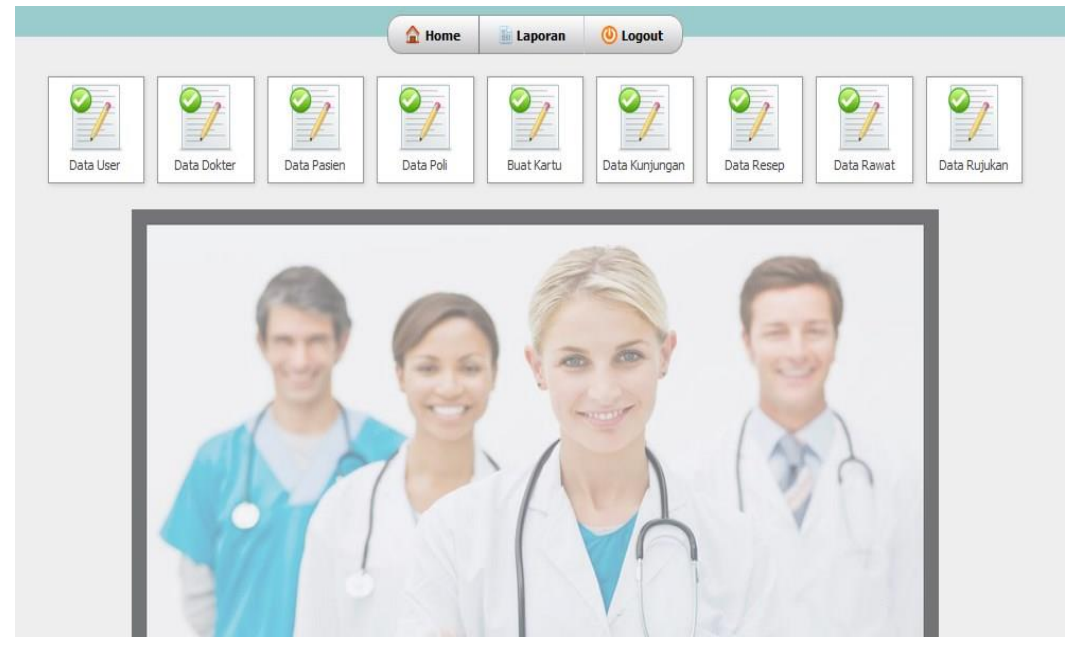

Gambar 3. Desain Form Menu Utama

\subsection{Form Login}

Form login dalam aplikasi ini bertindak sebagai pengaman aplikasi agar nantinya aplikasi tersebut di akses dan digunakan kepada pengguna yang berhak. Hal ini dilakukan agar menjaga keamanan dari aplikasi terjaga supaya pengguna nakal tidak mengacaukan sistem aplikasi yang kita buat

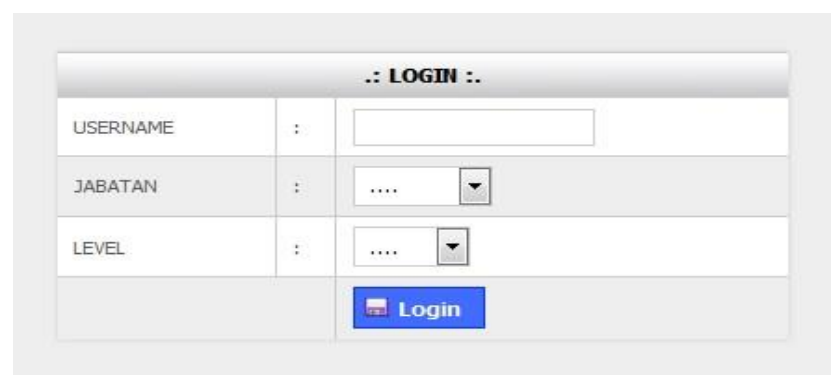

\section{Gambar 4. Desain Form Login}

\subsection{Form Input Data Pasien}

Form pasien bertujuan untuk memasukkan data pasien kedalam database, sebagai data pasien yang telah terdaftar.

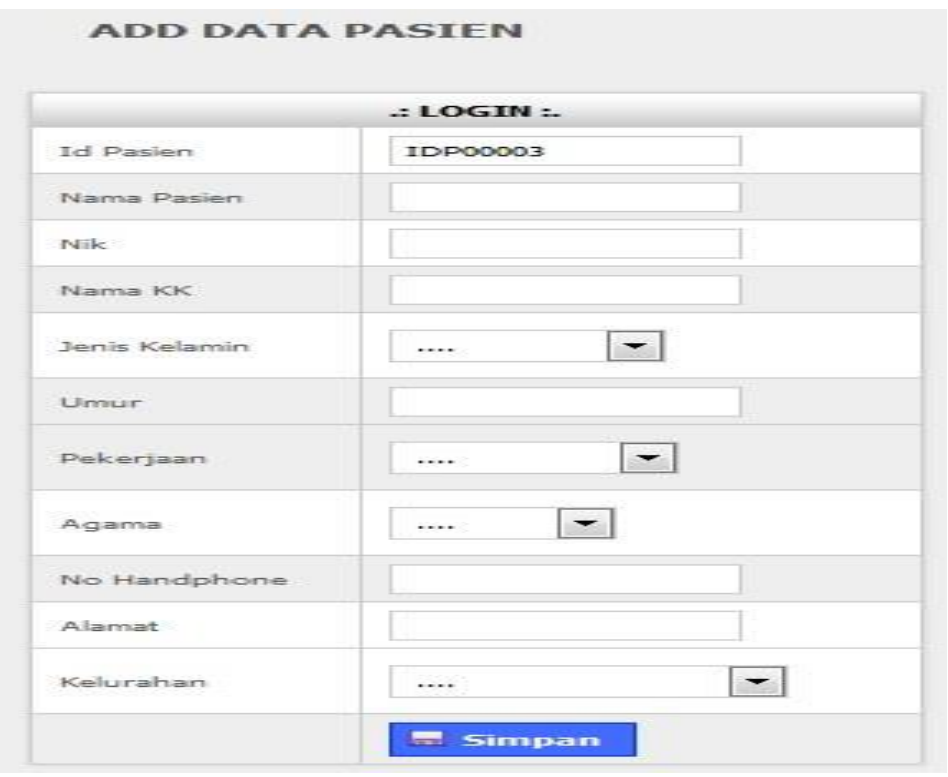

Gambar 5. Form Input Data Pasien

Setiawan, Analisa Dan Perancangan Sistem Informasi Pengolahan Data Pasien Rawat Jalan Berbasis Web Di Puskesmas Desa Tanah Merah 


\subsection{Form Data Pasien}

Form data pasien bertujuan untuk memasukkan data pasien kedalam database, sebagai data pasien yang telah terdaftar.

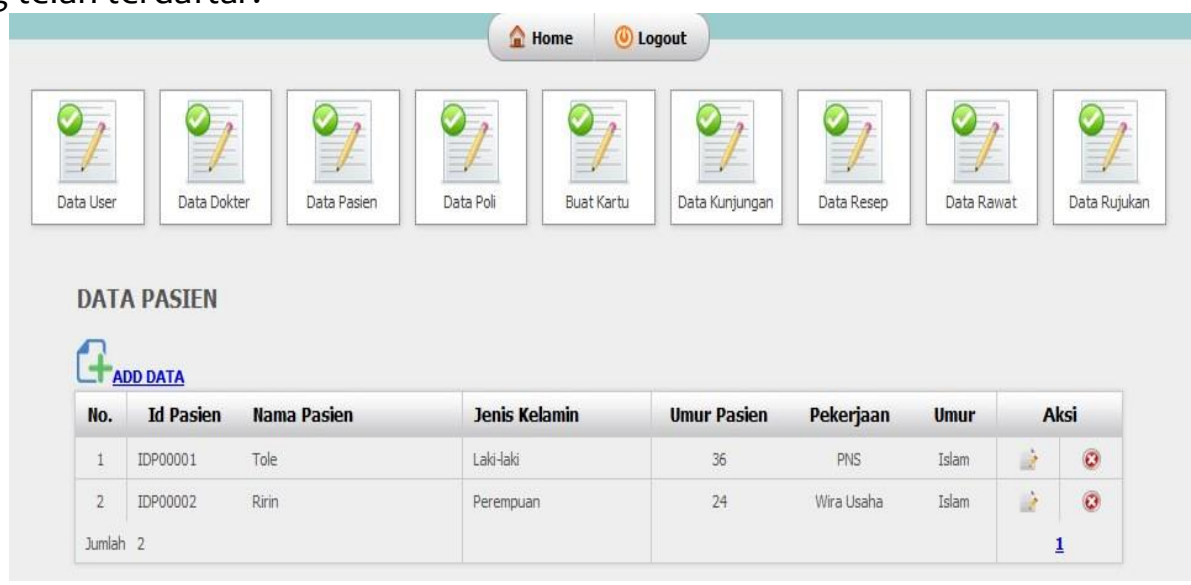

\section{Gambar 6. Form Data Pasien}

\subsection{Desain Output Laporan Rekapitulasi Kunjungan Pasien}

Desain keluaran merupakan hasil dari pengolahan, yang mana pengolahan dibuat dalam bentuk laporan. Adapun bentuk rancangan hasil dari keluaran data rekapitulasi kunjungan pasien tersebut adalah sebagai berikut:

\begin{tabular}{|c|c|c|c|c|c|c|c|c|}
\hline 迹? & & & & & $\begin{array}{l}\text { PITULASI } \\
\text { PUSKES }\end{array}$ & $\begin{array}{l}\text { JUNGAN PASIE } \\
\text { TANAH MERAF } \\
2016\end{array}$ & & \\
\hline No Nama Pasien & & LP & Unur & IdPasien & No Hp & Kartu Ketuaga & Alemat & Pelayynan \\
\hline 1 Rinin & & $P$ & 24 & DP00002 & 2147486567 & Amirir & Tembilahan & Kandungan \\
\hline \multicolumn{2}{|c|}{ Jumiah Data Pasien Berdasarian Jenis Kéamin } & & & \multicolumn{3}{|c|}{ Jumiah Data Pasien Berdassarizan Poli } & & \\
\hline Laki-aki & $: 0$ & & & \multicolumn{3}{|c|}{ Pof Anak } & \multicolumn{2}{|l|}{$: 0$} \\
\hline \multirow[t]{3}{*}{ Perempuan } & \multirow[t]{3}{*}{$: 1$} & & & \multicolumn{3}{|c|}{ Poí Gigi } & \multicolumn{2}{|l|}{$: 0$} \\
\hline & & & & \multicolumn{3}{|c|}{ Poil Umum } & \multicolumn{2}{|l|}{$: 0$} \\
\hline & & & & \multicolumn{3}{|c|}{ Poí Kandungan } & \multicolumn{2}{|l|}{$: 1$} \\
\hline
\end{tabular}

\section{Gambar 7. desain Output Laporan Rekap Kunjungan Pasien}

\subsection{Pengujian White Box Testing}

Dikenal juga dengan nama glass box, structural, clear box dan open box testing. Merupakan teknik testing perangkat lunak yang harus mengetahui secara detail tentang perangkat lunak yang akan di uji. Untuk pengujian yang lengkap maka suatu perangkat lunak harus diuji dengan white box.

\section{Kompleksitas Siklomantis}

Kompleksitas siklomatis merupakan metrik perangkat lunak yang memberikan pengukuran kuantitatif terhadap kompleksitas logis atau program, nilai yang didapat akan menentukan jumlah jalur independen dalam himpunan path, serta akan memberi nilai batas atas bagi jumlah pengujian yang harus dilakukan, untuk memastikan bahwa semua pernyataan telah diekseskusi sedikitnya satu kali. Berikut adalah perhitungan kompleksitas siklomantik dari source code pada form data pasien : 


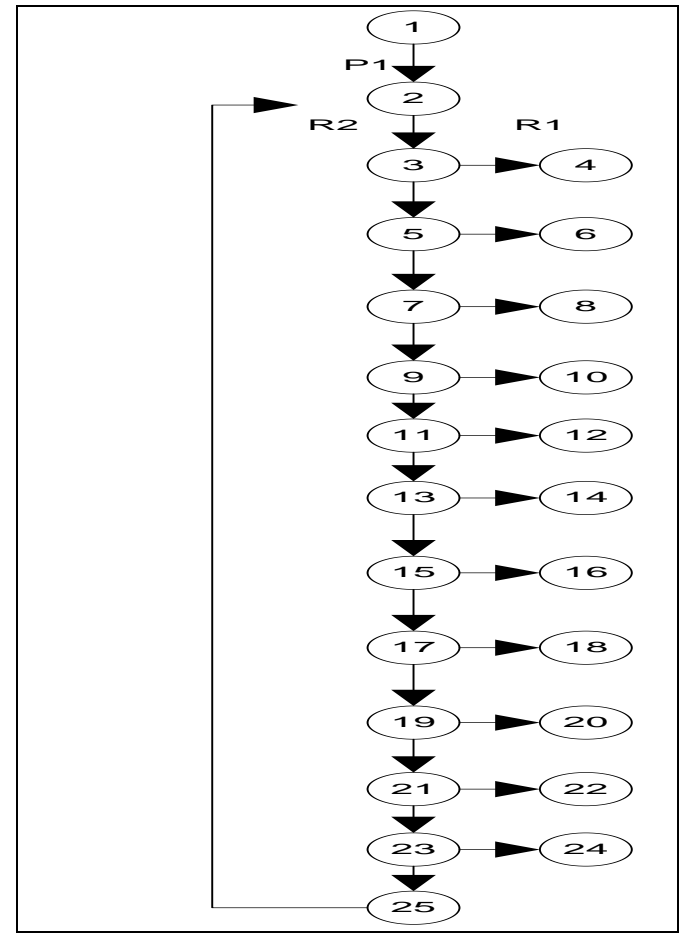

Gambar 8. Flow Graph Input Data Pasien

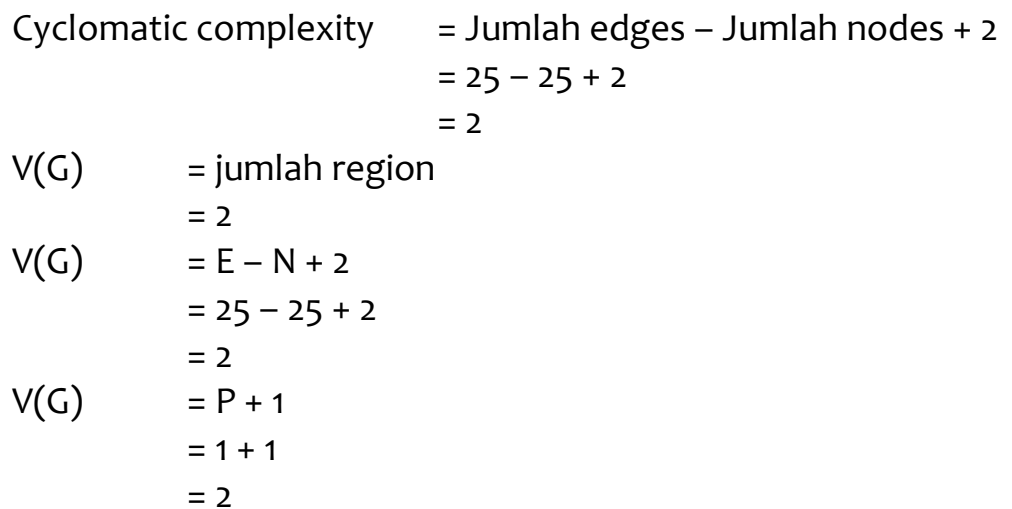

Jalur Independen :

Berikut adalah jalur independen pada Flow Graph pendaftaran siswa :

1. $1,2,25$

2. $1,2,3,5,7,9,11,13,15,17,19,21,23,25$

\section{KESIMPULAN}

Dengan adanya proses pembuatan sistem informasi ini, maka dapat disimpulkan perubahanperubahan yang terjadi didalam Pengolahan Data Pasien rawat jalan pada Puskesmas Desa Tanah Merah yaitu :

Pada sistem lama pengolahan data pasien pada puskesmas tanah merah masih dilakukan secara manual sehingga terjadinya kesalahan, pada sistem baru pengolahan data pasien dapat di oleh dengan efektif dan efisien karena aplikasi yang dibuat sudah tersistematis dengan baik dan benar

Proses sistem pencarian dan penyimpanan kartu pasien kurang efektif dan efisien karena disimpan pada lemari-lemari penyimpanan, pada sistem baru proses penyimpanan dan pencarian kartu pasien dapat dilakukan dengan mudah karena di simpan dalam satu sistem yang saling terhubung dan sistematis 
Pada sistem lama sistem yang sedang berjalan menyulitkan petugas puskesmas yang menangani data pasien dalam mengolah laporan data pasien puskesmas Tanah Merah, pada sistem baru setiap laporan yang berhubungan dengan data pasien sudah tersistem sehingga keakuratan dan ke amanan data pun tidak diragukan sehingga pembuatan laporan dapat dikerjakan dengan efektif dan efisien.

\section{REFERENSI}

Herlawati, W. (2011). Menggunakan UML. Bandung : Informatika

Hidayatuloh, P dan Kawistara, JK. (2014). Pemograman Web. Bandung : Informatika

Kadir, A. (2013). Pengenalan Sistem Informasi . Yogyakarta: ANDI

Komputer, W. (2011). Adobe Deamweaver CS 5 UntukBeragam Desain Website Interaktif. Semarang : Andi.

Kristanto, A. (2007). Perancangan Sistem Informasi Dan Aplikasinya. Yogyakarta: Gafamedia.

Lajamudin, AB. (2015). Analisis Dan Desain Sistem Informasi. Yokyakarta : Graha Ilmu

Lestari, E. (2011). Sistem Informasi Rekam Medik Pada Rumah Sakit Bersalin Graharap Tanjung Balai Karimun. Universitas Sriwijaya. JSI. Vol 3, No 2, Oktober 2011. ISSN : 2355-4614.

Nugroho, A. (2011). Perancangan Dan Implementasi Sistem Basis Data. Yogyakarta: Andi

Pressman RS. (2011). Rekayasa Perangkat Lunak. Yokyakarta : Andi

Raharjo, Budi Dkk. (2014). Modul Pemograman Web HTML, PHP dan MySql. Bandung : Modula

Rosa, AS. Dan Salahudin, M. (2013). Rekayasa Perangkat Lunak Terstruktur Dan Beroreantasi Objek. Bandung Informatika

Sidik,B. (2014). Pemograman Web dengan PHP. Bandung : Informatika

Susanto, G. (2012). Sistem Informasi Rekam Medis Pada Rumah Sakit Daerah (RSUD) Pacitan Berbasis Web Base STKIP PGRI Pacitan. IJCSS FTI UNSA VOL 9 No. 3 Desember 2012. ISSN 20880154 .

Susilo, D. (2010). Sistem Informasi Rekam Medik Di Poli Klinik PT Air Mancur. Universitas Sahit Surakarta. INFOKES VOL 1 No 1 Februari 2010. ISSN 2086-2628.

Sutabri, T. (2012). Konsep Sistem Informasi. Yokyakarta : Andi 